\title{
The practical benefits of planning
}

\author{
Douglas R McKay MD MBA FRCSC ${ }^{1}$, Daniel A Peters MD MBA FRSCS²
}

$\mathrm{I}^{\mathrm{n}}$ $\mathrm{n}$ this editorial, we explore concepts familiar to all surgeons but study them in the context of planning and optimizing business execution. We touch on the theoretical fundamentals of private surgical service pricing, and delve deeper into the background behind these choices. Ultimately, all business-based decisions are determined by your financial objectives and the resource limitations that constrain your ability to generate income. In the vernacular, these two concepts fall under the umbrellas of goal setting, and managerial or cost accounting.

\section{HOW MUCH MONEY DO YOU REALLY NEED?}

From your glory days as a high-school athlete to residency matching in plastic surgery, goal setting has played a fundamental roll in achievement. Goals met and missed generate information that validates or negates assumptions. This concept is pervasive in the business world. Stocks rise and fall when companies hit or miss the estimates of the institutional analysts. Corporations benchmark comparable peers to evaluate their ability to create shareholder value and allocate resources accordingly. The value of your RRSP oscillates as a result of goal setting. But few think to apply this simple and familiar financial concept to their practice.

Financial goals are essential to the design of your practice. Even if your goal is to make as much money as possible - it probably shouldn't be, but that's an unrelated story for a lifestyle column - your ability to execute this plan is still subject to constraints. Even when faced with the mixed blessing of unlimited resources, you will be constrained by time; there are only so many hours in a week, weeks in a month and months in a year. This notion, that scarce resources can be optimally allocated to generate income, forms the fundamental assumption of managerial or cost accounting.

\section{THE PROFIT MARGIN BROKEN DOWN}

Cost accounting is best explained with an example. Imagine a surgical instrument manufacturing company whose investors expect a specific return on their investment. This return becomes the goal. The company can manufacture a variety of instruments; some are expensive and some are not. But they cannot manufacture an infinite number of each. The process is subject to constraints, and the profit margin per unit (final unit price less per unit manufacturing cost) becomes the critical variable.

In manufacturing, raw materials, labour and overhead (electricity, water, support personnel, etc) are the constraints. With a bit of data from years past, a company estimates the number of hours of labour required, the material used and overhead needed to make each instrument. By subtracting this number from the market price, the profit margin per instrument is then multiplied by sales volumes to estimate the income generated by each. This is a powerful multiplier; it enables the company to plan for upcoming years and optimize profit in the face of constraint.

\section{BUT HOW CAN THIS HELP ME PLAN MY VACATIONS?}

The analogous application to practice is simple and the data are easy to access. Income and the expenditures that generate income can easily be pulled from past income and tax statements. A calendar from previous years provides the constraints. For most surgeons, these are the institutionally assigned number of clinic or office days, minor procedure days, main operating room (OR) days and nights on call. Combine the two using a basic spreadsheet program and a surgeon can begin to estimate income moving forward.

\section{MULTILINEAR REGRESSIONS, ARE YOU SERIOUS?}

Yes. Business people use the exact same statistical analyses we use for our randomized controlled trials to a financial end. If you break your billings down per month - or better - by weeks, you'll have a wealth of data. Take the income you generate and the number of days you spent in the office, clinic or the OR, and run your regression - an updated version of Excel and YouTube provides enough background information to do it by yourself. You will be able to estimate the average income each day in clinic, minors or the OR generates. If you multiply these numbers by your upcoming resource allocation, you can estimate your income moving forward.

And if you are clear with respect to your financial goals - mortgages, RESPS and investment savings - you can estimate how many days you need to work and, more importantly, how many days you can take off. You can determine if you want to do any cosmetic surgery, or you can decide how to price your services. And beyond this, you have a well-documented evaluation of your available resources. This will help you determine whether it's worth your while to open that new office, or allow you to make a business case-based appeal to your administration for more resources.

\section{CAVEAT EMPTOR}

Remember that all statistical analysis is subject to outliers and assumptions lie at the root of cost accounting. Predicting incomes down to hours worked is tough to do, but broad estimates will enable you to better plan all aspects of your career and life.

\footnotetext{
${ }^{1}$ Division of Plastic Surgery, Department of Surgery, Queen's University, Hotel Dieu Hospital Kingston; ${ }^{2}$ Division of Plastic Surgery, Department of Surgery and Telfer School of Management, University of Ottawa, Ottawa, Ontario

Correspondence: Dr Douglas R McKay, Division of Plastic Surgery, Department of Surgery, Queen's University, Hotel Dieu Hospital, 166 Brock Street,

Brock 3 R, B3031, Kingston, Ontario K7L 5G2. Telephone 613 544-3400 ext 2494, fax 613 544-3709, e-mail doug.mckay@utoronto.ca
} 